\title{
Older Adults' Experiences and Perceptions of Living with Bomy, an Assistive Dailycare Robot: A Qualitative Study
}

DOI:

10.1080/10400435.2021.1877210

\section{Document Version}

Accepted author manuscript

Link to publication record in Manchester Research Explorer

\section{Citation for published version (APA):}

Gasteiger, N., Ahn, H. S., Fok, C., Lim, J., Lee, C., MacDonald, B. A., Kim, G. H., \& Broadbent, E. (2021). Older Adults' Experiences and Perceptions of Living with Bomy, an Assistive Dailycare Robot: A Qualitative Study. Assistive Technology, 1-11. https://doi.org/10.1080/10400435.2021.1877210

\section{Published in:}

Assistive Technology

\section{Citing this paper}

Please note that where the full-text provided on Manchester Research Explorer is the Author Accepted Manuscript or Proof version this may differ from the final Published version. If citing, it is advised that you check and use the publisher's definitive version.

\section{General rights}

Copyright and moral rights for the publications made accessible in the Research Explorer are retained by the authors and/or other copyright owners and it is a condition of accessing publications that users recognise and abide by the legal requirements associated with these rights.

\section{Takedown policy}

If you believe that this document breaches copyright please refer to the University of Manchester's Takedown Procedures [http://man.ac.uk/04Y6Bo] or contact uml.scholarlycommunications@manchester.ac.uk providing relevant details, so we can investigate your claim.

\section{OPEN ACCESS}




\section{Older Adults' Experiences and Perceptions of Living with Bomy, an Assistive Dailycare Robot: A Qualitative Study}

Norina Gasteiger, Ho Seok Ahn , Christine Fok , JongYoon Lim , Christopher Lee, Bruce A MacDonald, Geon Ha Kim \& Elizabeth Broadbent

To cite this article: Norina Gasteiger , Ho Seok Ahn , Christine Fok , JongYoon Lim , Christopher Lee , Bruce A MacDonald, Geon Ha Kim \& Elizabeth Broadbent (2021): Older Adults' Experiences and Perceptions of Living with Bomy, an Assistive Dailycare Robot: A Qualitative Study, Assistive Technology, DOI: 10.1080/10400435.2021.1877210

To link to this article: https://doi.org/10.1080/10400435.2021.1877210

Accepted author version posted online: 05 Feb 2021.

Submit your article to this journal $\widetilde{ }$

Llll Article views: 37

Q View related articles $\sqsubset$

View Crossmark data 
Publisher: Taylor \& Francis \& RESNA

Journal: Assistive Technology

DOI: $10.1080 / 10400435.2021 .1877210$

\title{
Older Adults' Experiences and Perceptions of Living with Bomy, an Assistive Dailycare Robot: A Qualitative Study
}

Norina Gasteiger ${ }^{1}$, Ho Seok Ahn ${ }^{2}$, Christine Fok ${ }^{1}$, JongYoon Lim ${ }^{2}$, Christopher Lee ${ }^{2}$, Bruce A MacDonald $^{2}$, Geon Ha Kim ${ }^{3}$ \& Elizabeth Broadbent ${ }^{4 *}$

1. School of Population Health, The University of Auckland, Auckland, New Zealand

2. Department of Electrical, Computer and Software Engineering, The University of Auckland, Auckland, New Zealand

3. Department of Neurology, Ewha Womans University Mokdong Hospital, Ewha Womans University, College of Medicine, Seoul, South Korea

4. Department of Psychological Medicine, The University of Auckland, Auckland, New Zealand

*Corresponding author: Elizabeth Broadbent, Email: e.broadbent@auckland.ac.nz

\begin{abstract}
An ageing global population and preference for ageing-in-place pose the opportunity for homebased robots to assist older adults with their daily routines. However, there is limited research into the experiences of older adults using robots in their own homes. In this descriptive qualitative feasibility study, older self-supporting and community-dwelling adults with various age-related health needs used Bomy, a dailycare robot in their homes for up to one week. The study explored the usefulness of the robot and participants' perceptions and experiences of using it. Bomy reminded them of daily activities and delivered cognitive stimulation games. Semi-structured in-person interviews were conducted, and data were analyzed thematically. Findings revealed an acceptance toward robots and the value of assistive dailycare robots. Participants perceived Bomy as a companion and made suggestions for improvement, including resolving technical issues associated with long-term use. Future functions should be personalizable, to accommodate each user's health needs and could also include smoke detection and reading aloud functions. Dailycare robots show promising potential in elderly care, especially in providing reminders for medication, health and wellbeing. This study highlights the importance of co-design and testing robotics in the environments for which they have been developed. Widespread implementation of Bomy might be feasible in the future, with some further adjustments.
\end{abstract}




\section{Keywords}

assistive robots, human-robot interaction, older adults, geriatric, feasibility

\section{Introduction}

An ageing global population presents new challenges for supporting the health requirements of older people. Older adults often experience difficulties living with age-related physical and cognitive disabilities. This can place physical, emotional and financial burdens on families and residential care services. Activities such as brain training, social engagement and ageing-in-place may help to prevent cognitive decline and promote functioning (Clare et al., 2010; Klimova et al., 2017; Krueger, 2009). Self-supported ageing-in-place or within aged-care communities has positive benefits for social connection, social inclusion and the quality of life for older people (Barrett et al., 2012; Horner \& Boldy, 2008). This is because ageing-in-place ensures continuity of environment and promotes independent-living within the community, but with some assistance (Barrett et al., 2012; Horner \& Boldy, 2008).

The degree of assistance required varies by individual, but many older adults may need assistance with memory. Common reminders include managing medications (Jekel et al., 2015) and remembering daily activities (Lindbergh et al., 2016). Innovations in computer systems and robotic technology have accelerated the development of assistive robotic technology to support older adults with their daily living needs. A particular advantage of dailycare and home-based robots is their ability to support independent living and ageing-in-place. 
Dailycare service robots can provide social, non-physical assistance to older adults with daily functioning, including reminders (Matarić \& Scassellati, 2016). For example, the iRobi robot can remind older adults to take medications and do physical exercise, monitor health, and connect to family and care providers. iRobi has been tested in older people's homes for periods of three months to one year, with positive effects on medication adherence and reduced health care costs (Broadbent et al., 2018b; Orejana et al., 2015).

There is also the potential for robots to help prevent age-related cognitive decline by delivering cognitive stimulation activities (i.e. games), in addition to reminders (Ahn et al., 2014; Law et al., 2019a). This is evident in the CompanionAble robot, which provides reminders as well as cognitive training activities and video-calling. This robot was deemed useful and enjoyable to use, by five couples who tested it in their homes (Schroeter et al., 2013).

Other robots used by older adults at home include the agile Care-O-Bot (Graf et al., 2009) which performs fetch-and-carry tasks and Paro (Shibata \& Tanie, 2001) the companion seal. Paro has been found to lower blood pressure (Robinson et al., 2015) and reduce loneliness (Robinson et al., 2013) and reduce stress in older adults (McGlynn et al., 2016). Paro has been tested with older people living at home who attend dementia day-care facilities with positive effects on mood (Liang et al., 2017). These studies demonstrate that home-based robots can promote ageing-inplace, increase wellbeing and may alleviate the burden on the individual, their families, carers and aged-care facilities.

Despite the potential value of dailycare robots, very few studies have explored the unrestricted use of robots by end-users, in their natural home environments and perceptions of them thereafter (Pearce et al., 2012). Instead, researchers in clinical or experimental settings often supervise human-robot interaction between older adults and dailycare assistive robots. In a literature review on socially assistive robotics, Vandemeulebroucke et al. (2018) identify a lack of in-depth evaluations, as some researchers only provide users with a single session to test a robot or ask participants to imagine using it, after seeing it. For example, Pino et al. (2015) presented a multimedia PowerPoint presentation to their participants, to show images and videos of robots.

Bajones et al. (2019) and Zsiga et al. (2017) highlight the importance of evaluating robotics in the actual homes of end-users, as this is essential to encountering real-world challenges. Bajones et al. (2019) tested an autonomous mobile dailycare robot Hobbit in the homes of 16 end-users and found that participants interacted with the robot every day and perceived the robot valuable in 
providing elderly care. Similarly, eight older adults responded enthusiastically to a mobile companion robot evaluated by Zsiga et al. (2017), despite experiencing some technical issues associated with long-term use.

Few developers in the field of assistive robotics have partnered with stakeholders to co-design technology. Conventional top-down design processes tend to mismatch technologies with their users, resulting in older adults' needs and preferences not being fulfilled (Wang et al., 2019). It is essential to include older adults, carers and aged-care experts in a democratic manner from the conception of a technology to develop products that are appropriate, safe and accessible for their intended audiences (Vandemeulebroucke et al., 2018; Wang et al., 2019). User-centered codesign also has positive impacts on meaningful adoption and sustained use (Ritter et al., 2014; Scandurra \& Sjölinder, 2013).

The present study is part of a four-year collaboration between Ewha Womans University and the University of Auckland. The project seeks to co-design, develop and evaluate a home-based healthcare robot with and for older adults. In phase one, appropriate functions for a robot were determined through interviews with individuals, carers and experts in geriatric research or clinical care (Darragh et al., 2017). In phase two, nine experts and nine older adults watched video scenarios of a dailycare robot Silbot and responded to questions regarding the robot's appropriateness (Broadbent et al., 2018a; Law et al., 2019b). Phase three tested the acceptability and suitability of a dailycare robot after 10 experts interacted with it (Law et al., 2019b).

This article presents the subsequent and last phase of the project, which evaluates a dailycare robot through unrestricted and unsupervised use, in the homes of older adults for a week-long period. Older adults can provide valuable insight as to the specific challenges they face in their daily lives. Importantly, they can help to explain how robots could assist them to continue to live their lives as independently as possible within their homes. This study in phase four explores the feasibility of using a dailycare service robot in the homes of older community-dwelling adults. Feasibility studies tend to be conducted in the environments in which a product is intended to be used, to consider relevant factors that may influence successful use or implementation. Specifically, the present study explored the usefulness of the robot and participants' perceptions and experiences of using it.

\section{Methods}


The study has a qualitative, descriptive design. Ethics approval was granted from the University of Auckland Human Participants Ethics Committee in October 2019 (Reference: 283831). The research team consisted of a multi-disciplinary group of engineers, computer scientists, health researchers and psychologists. The two interviewers did not have existing relationships to the participants and had not worked on the previous projects in developing the dailycare robot, which helped to minimize bias.

\section{Context and Sampling}

The research was conducted in the homes of older adults at Selwyn Heights and Selwyn Village, two retirement villages in Auckland, New Zealand (NZ). Both villages have facilities and buildings where residents live independently (e.g. villas and apartments) and provide organized leisure and entertainment activities/events. On-site healthcare facilities are also available, including wellness centers, rest homes and hospital-level care. Selwyn Heights features 220 apartments and 24 villas, while 560 residents live at Selwyn Village. Data were collected from December 2019 to February 2020.

Participants were recruited via convenience sampling (Lavrakas, 2008). Staff at the villages handed out flyers to residents and allowed the researchers to present a seminar on health robots, speak at forums, include the advert in their newsletter and put adverts on noticeboards.

Recruitment was ongoing during the data collection process, but ended when saturation was met (the point at which no new themes emerge) (Glaser \& Strauss, 1967), after the sixth participant was interviewed. The two interviewers discussed the findings after each interview, to determine when saturation had been met. Saturation was therefore evident during the last interview, as the interviewers heard no new content emerging (Saunders et al., 2018).

Participants were eligible to participate if they were residents in the independent living sections of the retirement villages and were aged 60 years or older. They also needed to have an Internet connection in their homes as the robot needed to be connected to provide the reminders.

Likewise, participants had to score higher than 21 on the Mini-Mental State Exam (MMSE), which indicated normal cognition or mild cognitive impairment (Folstein et al., 1975).

\section{The Robot}


The robot, Bomy (version 2), was developed by Robocare (2019) and Ewha Womans University in South Korea and its functions were translated into English for this study (refer to Figure 1). The robot featured 2x1 DOF tilting wings with a pan/tilt touch-screen as a head. The robot could interact with users through text-to-speech (TTS) implemented by Google's TTS service. It was designed to be intuitive to use, with a large touch-screen and the ability to move. For this study, Bomy was stationary due to difficulties moving on thick carpet. The voice could be adjusted in regard to loudness and speed of speech.

Figure 1. Photographs of Bomy, the dailycare robot used in the study.

Six games were delivered on the robot, three screen-based games (using only the touch-screen) and three using additional interactive blocks (see Figure 2). The games include: Dressing Up, Cooking, Hide and Seek, Block Matching, Find It Quickly and Memory. Magnets were embedded within the 10 interactive blocks, so that they could be attached and detached to one another. Each block had a touch-screen surface with tactile sensors and visual display. The robot was able to detect the location of each block. Participants could use the blocks in their charging tray, or move them around on a table, based on the instructions from the robot. Each game had 10 levels, to challenge participants.

Figure 2. Photograph showing a screen game (above) and the interactive game blocks (below).

Nine types of reminders were also available on the robot (see Table 1). These could be set for any date and time and could include accompanying notes.

Table 1.

Types and descriptions of the daily reminders.

\section{Data Collection Procedures}

Interested participants were screened for eligibility. Researchers administered a prescreening questionnaire about the inclusion criteria and administered the MMSE (Folstein et al., 1975) to assess cognitive functioning. Individuals who met the inclusion criteria were given an information sheet and asked to sign a consent form. This session took place in the participants' homes. 
Bomy was set up by the researchers in the living room of participants, usually on a small coffee table. Researchers programmed the robot with the reminders each participant chose, using a web browser. They also taught the participant how to use the robot, especially turning it on and off, charging it, playing the games and reacting to the reminders.

The robot was used in the home of the participants for up to one week (seven days). During this time, participants were able to contact the researchers via mobile phone and email to remove the robot from their homes or assist with technical issues. Participants were asked to use Bomy as often as they desired. At the end of the week, the researchers collected Bomy and conducted semi-structured and audio-recorded interviews at the home of the participant. Interviews lasted up to 60 minutes and explored the use of the robot and perceptions of usefulness. A NZ \$20 voucher was given to each participant as a token of appreciation.

Interviews, rather than observations were deemed appropriate to collect the data. This is because interviews are based on a type of inquiry that seeks to explore perceptions from the informant's subjective experience and lived reality (Buetow, 2007; Denzin \& Lincoln, 2011; Minichiello et al., 1990). In contrast, observations focus on the researcher's interpretation of behavior and thus fail to explore subjective experience.

The strategy of member-checking was included in the interviews, to ensure credibility and confidence that the findings hold truth (Creswell, 2007). This was performed at the end of the interview, whereby the interviewer provided a verbal summary of the interview and invited the interviewees to correct or clarify the summary. Interviewees also had the opportunity to review and alter their transcripts so that their data accurately reflected their experiences and perceptions. Audio-recordings were transcribed verbatim.

\section{Data Analysis}

The data were analyzed thematically through an inductive process. The coding and theme development process was therefore directed by the content of the data, rather than by applying predetermined frameworks or theories. The specific method of thematic data analysis adhered to the Braun and Clarke (2006) framework for manual qualitative data analysis. The two researchers who had conducted the interviews first familiarized themselves with the interview transcripts by reading and re-reading each transcript. They then independently coded the data. This included 
assigning codes to identify and represent important features of the data. Codes specifically related to the research question and aims of the study. Information that did not relate to the robot, usefulness or experiences and perceptions of using it was disregarded. This mostly included comprehensive accounts of medical history and conversations about daily life. Having multiple coders ensured consistent and reliable interpretations of the data and ensured inter-rater reliability (Thomas \& Harden, 2008). Inter-rater reliability is the extent to which raters agree on the codes. This was determined through consistent judgment and an absence of disagreement between the coders (Boyatzis, 1998).

Initial themes were generated during an in-person meeting by identifying patterns across the codes. The initial themes were discussed until consensus was met. After this, the themes were reviewed against the transcripts and the research questions and aim. This included combining, removing and splitting themes and ensured that the themes answered the research question and also accurately represented the perspectives and experiences of the participants. Lastly, themes were defined and supported by quotes from the transcripts. The final themes provided a balanced description of participants' perceptions of and experiences with using the robot.

\section{Results}

\section{Participant Summary}

Seven residents were recruited, however one did not participate due to a hospitalization that rendered her ineligible, as she moved to a care facility. A total of six older adults participated in the study.

Participants were aged between 72 and 83 years $(M=78)$. Four participants identified as female and two as male (See Table 2). Participants identified as NZ European, English and Welsh and had lived in retirement villages between 1 and 6.5 years. MMSE scores ranged between 24 and $29(M=27.5)$, with five participants presenting normal cognitive functioning and one participant scoring as having a mild cognitive impairment (MMSE score <25). Participants reported living with various health needs, including vision-impairment, tinnitus, memory and hearing concerns and requiring multiple medications (including prescribed and over-the-counter medications and supplements). Three individuals met the criteria for polypharmacy (taking more than five medications). Three others self-performed daily blood pressure monitoring and two attended rehabilitation services, including physiotherapy. 
Four participants had the robot in their homes for the full seven days, and two did not turn it off at all. Of the two participants who ended the study prematurely, one cited problems with the technology and the other left town to visit family. All six participants played the games and chose to have reminders for medications, such as taking pills and doing daily blood pressure checks (using a personal at-home blood pressure monitor). No participants decided to have reminders for recommendations, the block games or surveys. Three participants chose to have the wake-up reminders, robot game reminders, go out, visit and go to bed reminders. On average, participants used 3.6 different reminders (range: $2-5$ ).

Table 2. Summary of participants' demographics and time using the robot.

\section{Themes}

Five overarching themes emerged from the analysis of the data. These included (1) acceptance of robots, (2) value of the reminders, (3) companionship, (4) digital confidence and technical support and (5) room for improvement.

\section{Theme 1. Acceptance of Robots}

Most participants were accepting of robots in general. This meant that participants deemed them "fun" and useful to society, both on an industrial level and for household use. Their use as tools and equipment was often highlighted, and most participants perceived robots as ongoing prototypes. They were, therefore, accepting that they would have some "teething" problems until they were developed on a mass scale.

I think they're fun- I do! (P5)

I can imagine that all robots are going to have a lot of teething trouble until somebody really gets down to manufacturing them on scale and sorting everything out about them. (P4)

\section{Theme 2. Value of the Reminders}

The reminders function of the robot was perceived by most participants as useful. Participants thought that any health-related reminders were most helpful and could be useful in helping them manage their health needs. These included taking medications, reminders for exercise, and taking blood pressure for self-monitoring purposes.

There were things like blood pressure [reminders] that were really useful. (P4) 
Participants identified that the reminders function would be even more useful for other end-users, especially those with co-morbid and complex health needs, lower levels of cognitive functioning, those who are dependent on help or reminding and those who do not have access to other technologies that can give reminders.

But that could be useful I believe if you were relying on it and had various things to put into it. (P4)

One participant identified another resident of the village who would most benefit from the reminders. She thought that the woman would benefit as she was struggling, especially in managing her medication schedule. According to the participant, the woman often mixed her medicines, as she could not remember how to take them. The participant thought that Bomy would be useful for her, as it could remind her when and how to take her medications and may even mean that she did not need to go into care or receive human support for this:

I'm thinking of a woman I befriend here ... she's 90 and she's struggling and I go down there and I watch her with her pills and I think < gasp> she's muddling them up and she's sorting them, going "I'm going to have two of this today and I'm not going to have this one." This lady would benefit hugely [from the robot] and whereas I'm thinking she needs care of some sort, this is the sort of thing that would help her to not need care. That would be her sort of care. (P2)

\section{Theme 3. Companionship}

More than half of the participants perceived Bomy as a companion or friend. They named the robot and spoke to it. Some also patted it. Two participants had dressed Bomy up with a Santa hat, for the Christmas holidays. Some participants had subconsciously assigned a gender to Bomy, often referring to it as "he" in their speech.

He was another friend. (P3)

Well, I quite liked it! < Laughs $>$ I thought of it as a little friend that you could pat and talk to. Really, yes, I thought that was it and was quite happy with it. I would be happy to keep it. (P5)

One participant identified that Bomy would be a particularly useful companion to somebody who is shy and does not socialize often. This is because the robot is not a human, and so does not make negative judgments on what someone looks like or what they are wearing.

For those people who are a bit shy maybe or just don't like mixing with people then it could be useful... Because it's not the human person, and the robot does not make any judgment on what they're wearing, what they look like, what their hair is like - just no judgments. (P6). 


\section{Theme 4: Digital Confidence and Technical Support}

Most of the participants reported that a lack of digital confidence would create barriers to using Bomy. Digital confidence was characterized by their self-confidence in their abilities to learn to use the robot and remember how to use it. They highlighted that using robots can be a steep learning curve without digital confidence and experience in using technology. Participants spoke of intergenerational differences between those who were younger and more confident with technology and those their age, who may struggle more. They expected that future residents of retirement homes would adapt to newer technologies like robots more easily, as they will have experience using technologies.

Every year more people are going to be more technology savvy as they come up through into retirement villages.... They're used to working with technology. They've got robots in businesses now so some people will be much more familiar with how they work (P3).

Participants expected that ongoing technical support would help them to obtain digital confidence to use Bomy. They thought that this support should be ongoing, as they often forget how to use technology. Similarly, more technical support would be required when inputting the reminders in the future, as residents may struggle with doing it themselves. This was expected to be particularly difficult if people with lower levels of cognition used it, as they would likely forget how to program the robot. Instead, their carers, family or support staff should input the reminders on their behalf. Overall, participants were optimistic that others could also learn to use Bomy. This was highlighted by a resident who stated that others could learn to use it, as she had.

I don't see that for most people it should be difficult. I mean, if I can use it then they can do $i t !(P 5)$

\section{Theme 5. Room for Improvement}

Participants made suggestions for improving Bomy. Three sub-themes for the improvements were evident: (1) technical issues, (2) robot features, and (3) the simplicity of the games.

Participants reported some technical problems that frustrated them. Issues included the game blocks sometimes not responding and a lagging or unresponsive screen. These issues required troubleshooting (mostly turning the robot or blocks on and off). However, despite these problems, they saw value in Bomy and wanted to play the games more.

I liked playing with the blocks, but the blocks did keep bombing out on me. So that was disappointing because I wanted to do more. (P3) 
All participants identified room for improvement in Bomy's features, to accommodate their health needs. These included the noise and voice of the robot, its size and mobility and adding additional features.

Three participants thought the robot and the charger were too noisy, due to the built-in fan. The noise was likened to a humming sound, but would be silenced when the robot was turned off. The humming noise was also reported to exacerbate one resident's symptoms of tinnitus.

I just couldn't stand the noise of it. So apart from putting it on and playing the games I had to quickly put it off again. (P6)

The voice was also identified as something that could be improved. According to some participants, Bomy's voice was too machine-like and robotic, rather than human-like.

Accordingly, this sometimes made it difficult to understand, especially for residents with hearing concerns.

Most of the participants perceived that Bomy was fairly big for their small apartments and would be challenging to move around. Many thought the size would be justified if the robot were mobile and that the volume of it would then have a certain value, regarding sturdiness. Participants also highlighted safety issues for vision-impaired residents, who would struggle to move around the robot and know where it is, especially if it were mobile.

A lot of my friends are almost blind you know, and they can just see, and they know where everything is. That would be annoying if there was something moving around the house...Yeah I think if it was walking around it could become a hazard, in a rest home. (P3)

More than half of the participants identified some other features that could be added to improve Bomy and make it more useful in supporting their daily needs. Participants believed that it could have the potential for improving accessibility and safety. Accessibility was spoken about in regard to being able to respond to voice commands or to function as a TTS transcribe, particularly for those with visual impairments. Participants especially envisioned Bomy reading books or recipes aloud to them.

For me personally, the robot could help with cooking.... it could just help with telling you recipes. (P6)

Some participants also thought that the robot could help with safety, such as by realizing dangerous situations and conveying these to the user, particularly for those who may struggle to live independently and are forgetful. Some examples included reminding the user to lock the door or realizing when food is burning before the smoke alarm is triggered. 
If it can be mobile and just go and pick up things that need to be done then that's another future possibility for it. Well, for example, it can go and say "the door is unlocked, come and lock the door." Something of that nature. It can tell you when the person making toast is trying to set fire to the place. Hopefully, before the fire alarm goes off. (P4)

Half of the participants reported that the robot games were too simple and not challenging enough. In general, participants preferred the interactive blocks to the screen-based games. This is because the blocks were perceived as more challenging and exciting. However, two of the other participants disagreed and enjoyed the games. They identified that they do what they are supposed to, which is to make the user think.

I think the games would be quite good. They made you think. (P5)

Discussion

This study explored the feasibility of using Bomy, a dailycare service robot in the homes of older community-dwelling adults. Specifically, the study explored the usefulness of the robot and participants' perceptions and experiences of using it to support their daily living needs. Overall, findings revealed a general acceptance toward robots and an appreciation of the value of assistive dailycare robots, like Bomy. An unexpected benefit was Bomy's ability to act as a companion.

Participants valued the personalized medication and health-related reminders the most. These were expected to be especially helpful for other end-users who may depend on reminding, due to lower levels of cognitive functioning. Participants made suggestions for improving the robot so that it could accommodate their various health-related needs. This included resolving some technical issues, making the games more stimulating and amending the robot's voice and size. These amendments were expected to make Bomy more appropriate for older adults, especially those with vision and hearing impairments. Ongoing technical support is also needed, especially for older adults who have limited experience in using technology or have advanced cognitive decline that would make remembering to use the technology difficult.

This study contributes to limited literature evaluating robotic assistive technology in the homes of the users it was developed for (Bajones et al., 2019; Broadbent et al., 
2018b; Broadbent et al., 2014; Coşar et al., 2020; Robinson et al., 2014; Zsiga et al., 2017). Previous research has presented expectations for the functions a dailycare robot should perform, including helping to dress residents, setting tables, turning off taps, making beds, alerting for help, detecting fires, providing medication and exercise reminders and locking doors (Broadbent et al., 2012; Darragh et al., 2017). The residents in our study also identified detecting fires and locking doors, but were more conservative in their suggestions, possibly as they had used the technology and in doing so, understood its limitations. Research by Broadbent et al. (2012) also found that residents wanted dailycare robots to be five feet tall and robust. They thought they would not want to play games with a robot. However, our study found the opposite, whereby after living with the robot, residents desired a smaller size and particularly enjoyed the block games.

Unrestricted and unsupervised use in the homes of participants was also essential to uncovering technical issues that were not evident in previous lab-based testing, such as the noise of the charger. Similarly, issues with the lagging screen and unresponsive blocks may have been a result of long-term and continuous use. This was also reported by Zsiga et al. (2017), whereby lengthy use of their robot caused technical errors. Accordingly, this can be attributed to most robot software operating systems not being designed nor intended for long-term operation (Zsiga et al., 2017). This is an important consideration for future long-term use of assistive robotics and may be overcome by users regularly re-starting the robot.

Our findings were consistent with previous research showing positive responses and perceived usefulness of a dailycare robot that can provide personalized daily reminders, as well as deliver cognitive stimulation games (Coşar et al., 2020; Schroeter et al., 2013). Participants particularly valued the medication and health reminders, which is also reflected in literature (Coşar et al., 2020; Law et al., 2019b). Medication and health reminders in assistive technologies are a valuable tool to support health systems, as non-adherence (i.e. due to forgetfulness and polypharmacy) is predicted to cost up to $\$ 7$ billion in Australia, and $€ 1.25$ billion in Europe annually (AIHW, 2016; Pharmaceutical Group of the European Union, 2008). Non-adherence also has direct health implications and may cause up to $10 \%$ of hospitalizations for older adults (Sokol et al., 2005).

Additional to the reminders and games, Bomy was found to provide companionship. This was somewhat surprising as the dailycare robot was intended to be assistive in nature, rather than act as a companion. However, this finding is similar to previous research that has shown that older 
adults found companionship with the healthcare robot $i R o b i$, used in their homes for medication management (Broadbent et al., 2014; Orejana et al., 2015). Although companion robots already exist, such as Paro (Shibata \& Tanie, 2001), Icat (Heerink et al., 2006) and Homie (Kriglstein \& Wallner, 2005), there may be value in exploring how to incorporate human qualities such as friendship into other assistive robots. Indeed, limited research has begun to investigate this (Johanson et al., 2019).

Evidently, Bomy met the balance between looking serious but friendly. Companion robots are often animal-like, and healthcare robots are better received when they have a serious appearance (Robinson et al., 2014). It is also important that robots do not look too human-like, as this may make users feel anxious and fear that they will replace humans (Cresswell et al., 2018). Ultimately, the perceived friendship between residents and Bomy may have influenced the general acceptance and positivity toward the robot, despite some technical issues.

Providing assistive technologies to older adults can be beneficial, but having to take these technologies away at the end of the research can pose ethical issues. For example, research on the companionship robot Paro found that some participants became distressed when the robot was removed (Moyle et al., 2017). Sharkey and Sharkey (2010) state that although some robots rely on deception (e.g. by posing as real animals) to be effective, they may improve the social lives of older adults. In another study, symptoms of depression increased at follow-up, after Paro had been removed (Liang et al., 2017). This is an important consideration in robot evaluation and highlights a need to clearly inform participants when long-term use beyond the study is not possible. Consideration should be given as to whether researchers and aged care facilities can provide options for participants to rent or purchase robots after studies have ended. Other considerations include a trial period of withdrawal, so that users can experience life without the robot again (Draper \& Sorell, 2017). In the present study, researchers clearly defined the one-week study period to participants, but had not expected participants to become attached to the service robot.

Widespread implementation and mass use of Bomy in the future was considered by participants, especially for other people with polypharmacy or cognitive impairments who rely on reminding. However, ongoing technical support was perceived as crucial to successful implementation. This finding is consistent across literature on health robots (Broadbent et al., 2018b; Cresswell et al., 2018; Frennert et al., 2020). Interestingly, inter-generational differences in digital confidence were acknowledged. This is reflected in the idea of 'digital natives' or generations who have grown up with technologies being more comfortable with them, compared to 'digital immigrants' who have limited experience in using them and find it harder to use them (Prensky, 2001). For 
Bomy, this could be overcome by having a family member or employee from residential living facilities program the reminders. Clinical or allied health staff could also input reminders for future appointments and medications. This can be done remotely using a web browser.

This study uncovered the need for further co-design and home-based unsupervised evaluations of robots by older adults. Older adults are not a homogenous group, and their daily living needs differ. The participants in this study lived with a multitude of health needs, including mild cognitive impairment, vision and hearing impairments and complicated medicine, health monitoring and rehabilitative schedules. Future design and development of dailycare robots should focus on technology that is quiet, friendly looking and personalized to respond to diverse daily living and healthcare needs. Personalizable functions are essential, as it is both impractical and impossible to expect users to adapt their lives significantly in order to live with a robot or to develop one robot that can cater to all health needs.

Functions like mobility should be decided upon in collaboration with the user, as vision-impaired older adults may struggle to know where the robot is. In this case, the robot could be stationary or communicate its location. Similarly, the robot should speak the language of the user and have an adjustable volume and speed for older adults with hearing difficulties. Features such as reading aloud via TTS could be added, to cater to vision-impaired users. A similar TTS feature is available in the ENRICHME robot, which reads the weather forecast (Coşar et al., 2020). Further co-design and home-based evaluation of assistive robots are needed to determine how these functions should be personalized, as it is difficult for developers and engineers to imagine the health needs and lived experiences of older adults (Vandemeulebroucke et al., 2018; Wang et al., 2019). It is also important that future co-design involves carers, as they will be supporting older adults with using the technology.

Limitations and strengths of this study must be acknowledged. Self-selection bias may have been evident, as participants volunteered to test the robot. This may have resulted in a group of participants who are more accepting of technology and robots in general. Additionally, many participants stated that they thought the robot would be more useful for others (e.g. specific friends or people with cognitive impairment. This limits the ability to truly evaluate the potential for adoption.

Although the sample size was relatively small, the qualitative data was rich and detailed. Similar research exploring human-robot interaction and evaluating assistive technology included studies 
with a one-off interaction with a robot and small sample sizes, with between one and 26 participants (Bemelmans et al., 2012; Graf et al., 2009; Law et al., 2019a; Louie \& Nejat, 2020; Orejana et al., 2015; Ros \& Espona, 2020; Zsiga et al., 2017). Major issues with technology can be identified in sample sizes of five participants (Graf et al., 2009). This research adds to previous evaluations that were limited by asking participants to imagine using the robot, rather than actually using it (Vandemeulebroucke et al., 2018).

Methodological strengths include the strategy of member-checking and having two independent coders with different academic backgrounds (public health and audiology) analyzing the data (Cresswell et al., 2018; Thomas \& Harden, 2008). This ensured inter-rater reliability and resulted in findings being interpreted accurately and holding truth (Thomas \& Harden, 2008). Many participants made notes about the robot during their week and read these out during the interview. This, along with unsupervised use of Bomy may have eliminated potential social desirability bias. In this study, useful recommendations and considerations for accommodating the various healthrelated needs of older adults in assistive robots can be made. These are transferable beyond this robot and have implications for the development and evaluation of future assistive robotic technology.

\section{Conclusions}

This study supports previous literature on the importance of co-designing and testing healthcare robots in the environments for which they have been developed. Unsupervised, unrestricted and longer-term use by older adults highlighted that implementation of Bomy may be feasible in the future, with some further adjustments to the games and technology, to accommodate age-related health needs. Suggestions for the robot's features and cognitive stimulation games may be useful for the development of future dailycare robots and assistive technology for older adults. Despite room for improvement, the dailycare robot showed potential in elderly care, especially in providing reminders for medication, health and wellbeing. Bomy is expected to be especially useful for people who rely on reminding, such as those with cognitive decline. Further amendments to the technology, especially personalized functions will increase the usefulness of Bomy in promoting independent living among older adults.

Word count: 6,330 (abstract to conclusion)

\section{Acknowledgements}

This work is part of a collaboration between the Centre for Automation and Robotic Engineering Sciences, the University of Auckland, New Zealand and Ewha Womans University, South Korea. 
The project was supported by the Ministry of Trade, Industry and Energy (MOTIE, Korea) under Industrial Technology Innovation Program (Reference: 5000667). Funders played no role in data collection, interpretation or reporting.

\section{Funding}

The project was supported by the Ministry of Trade, Industry and Energy (MOTIE, Korea) under Industrial Technology Innovation Program (Reference: 5000667).

\section{Conflicts of interest}

The authors declare that they have no conflicts of interest.

\section{References}

Ahn, H., Santos, M., Wadhwa, C., \& MacDonald, B. (2014). Development of brain training games for a healthcare service robot for older people.

AIHW. (2016). Health and welfare expenditure series no.57. Cat. No. Hwe 67. Retrieved from Canberra:

Bajones, M., Fischinger, D., Weiss, A., de la Puente, P., Wolf, D., Vincze, M., . . Frennert, S. (2019). Results of field trials with a mobile service robot for older adults in 16 private households. ACM Transactions on Human-Robot Interaction, 10. doi:10.1145/3368554

Barrett, P., Hale, B., \& Gauld, R. (2012). Social inclusion through ageing-in-place with care? Ageing \& Society, 32(3), 361-378. doi:10.1017/S0144686X11000341

Bemelmans, R., Gelderblom, G., Jonker, P., \& De Witte, L. (2012). Socially assistive robots in elderly care: A systematic review into effects and effectiveness. J Am Med Dir Assoc, 13(2), 114-120. doi:10.1016/j.jamda.2010.10.002

Boyatzis, R. (1998). Transforming qualitative information: Thematic analysis and code development. London: SAGE.

Braun, V., \& Clarke, V. (2006). Using thematic analysis in psychology. Qualitative Research in Psychology, 3(2), 77-101. doi:10.1191/1478088706qp063oa

Broadbent, E., Ahn, H., Kerse, N., Peri, K., Sutherland, C., Law, M., . . Kim, G. (2018a). Homecare robots for early stage dementia. Paper presented at the TechMindSociety 2018. APAScience '18: Technology, Mind, and Society, Washington DC, USA.

Broadbent, E., Garrett, J., Jepsen, N., Li Ogilvie, V., Ahn, H., Robinson, H., . . MacDonald, B. (2018b). Using robots at home to support patients with chronic obstructive pulmonary disease: Pilot randomized controlled trial. JMIR, 20(2), e45. doi:10.2196/jmir.8640

Broadbent, E., Peri, K., Kerse, N., Jayawardena, C., Kuo, I., Datta, C., \& MacDonald, B. (2014). Robots in older people's homes to improve medication adherence and quality of life: A randomised cross-over trial. Paper presented at the International Conference on Social Robotics, Cham.

Broadbent, E., Tamagawa, R., Patience, A., \& Knock, B. (2012). Attitudes towards health-care robots in a retirement village. Australasian Journal on Ageing, 31(2), 115-120. doi:10.1111/j.1741-6612.2011.00551.x

Buetow, S. (2007). Health research methods: A tabular presentation. New York: Nova Science.

Clare, R., King, V., Wirenfeldt, M., \& Vinters, H. (2010). Synapse loss in dementias. Journal of Neuroscience Research, 88(10), 2083-2090. doi:10.1002/jnr.22392

Coşar, S., Fernandez-Carmona, M., Agrigoroaie, R., Pages, J., Ferland, F., Zhao, F., . . Tapus, A. (2020). Enrichme: Perception and interaction of an assistive robot for the elderly at home. International Journal of Social Robotics. doi:10.1007/s12369-019-00614-y

Cresswell, K., Cunningham-Burley, S., \& Sheikh, A. (2018). Health care robotics: Qualitative exploration of key challenges and future directions. Journal of Medical Internet Research, 20(7), e10410. doi:10.2196/10410 
Creswell, J. (2007). Qualitative inquiry and research design: Choosing among five traditions (ed. 2). Thousand Oaks, CA: SAGE.

Darragh, M., Ahn, H., MacDonald, B., Liang, A., Peri, K., Kerse, N., \& Broadbent, E. (2017). Homecare robots to improve health and well-being in mild cognitive impairment and early stage dementia: Results from a scoping study. JAMDA, 18(12), 1099:e1091-1094. doi:10.1016/j.jamda.2017.08.019

Denzin, N., \& Lincoln, Y. (2011). Introduction: The discipline and practice of qualitative research. In N. Denzin \& Y. Lincoln (Eds.), The sage handbook of qualitative research (4 ed., pp. 1-20). United States of America: SAGE.

Draper, H., \& Sorell, T. (2017). Ethical values and social care robots for older people: An international qualitative study. Ethics and Information Technology, 19, 49-68. doi:https://doi.org/10.1007/s10676-016-9413-1

Folstein, M., Folsten, S., \& McHugh, P. (1975). Mini-mental state: A practical method for grading the cognitive state of patients for the clinician. Journal of Psychiatry Research, 12(3), 189-198. doi:10.1016/0022-3956(75)90026-6

Frennert, S., Aminoff, H., \& Östlund, B. (2020). Technological frames and care robots in eldercare. International Journal of Social Robotics. doi:10.1007/s12369-020-00641-0

Glaser, B., \& Strauss, A. (1967). The discovery of grounded theory: Strategies for qualitative research. Chicago: Aldine.

Graf, B., Reiser, U., Hägele, M., Mauz, K., \& Klein, P. (2009). Robotic home assistant care-obot ${ }^{\circledR}$ 3-product vision and innovation platform. Paper presented at the Proceedings of the IEEE Workshop on Advanced Robotics and Its Social Impacts

Heerink, M., Krose, B., Evers, V., \& Wielinga, B. (2006). The influence of a robot's social abilities on acceptance by elderly users. Paper presented at the The 15th IEEE international symposium on robot and human interactive communication, Hatfield, UK.

Horner, B., \& Boldy, D. (2008). The benefit and burden of "ageing-in-place" in an aged care community. Australian Health Review, 32(2), 356-365. doi:10.1071/ah080356

Jekel, K., Damian, M., Wattmo, C., Hausner, L., Bullock, R., Connelly, P., . . Frohlich, L. (2015). Mild cognitive impairment and deficits in instrumental activities of daily living: A systematic review. Alzheimer's Research \& Therapy, 7(1), 17. doi:10.1186/s13195015-0099-0

Johanson, D., Ahn, H., MacDonald, B., Ahn, B., Lim, J., Hwang, E., . . Broadbent, E. (2019). The effect of robot attentional behaviors on user perceptions and behaviors in a simulated health care interaction: Randomized controlled trial. Journal of Medical Internet Research, 21(10), e13667. doi:10.2196/13667

Klimova, B., Valis, M., \& Kuca, K. (2017). Cognitive decline in normal aging and its prevention: A review on non-pharmacological lifestyle strategies. Clinical Interventions in Aging, 12, 903-910. doi:10.2147/CIA.S132963

Kriglstein, S., \& Wallner, G. (2005). Homie: An artificial companion for elderly people. Paper presented at the The CHI'05: Conference on Human Factors in Computing Systems, Portland, Oregon.

Krueger, K. (2009). Social engagement and cognitive function in old age. Experimental Aging Research, 35(1), 45-60. doi:10.1080/03610730802545028

Lavrakas, P. (2008). Convenience sampling: SAGE.

Law, M., Ahn, H., MacDonald, B., Vasjakovic, D., Lim, J., Lee, M., . . Broadbent, E. (2019a). User testing of cognitive training games for people with mild cognitive impairment: Design implications. In Salichs M et al. (Ed.), Social robotics. Icsr 2019. Lecture notes in computer science (Vol. 11876). Springer: Cham.

Law, M., Sutherland, C., Ahn, H., MacDonald, B., Peri, K., Johanson, D., . . Broadbent, E. (2019b). Developing assistive robots for people with mild cognitive impairment and mild dementia: A qualitative study with older adults and experts in aged care. BMJ Open, 9(9), e031937. doi:10.1136/bmjopen-2019-031937 
Liang, A., Piroth, I., Robinson, H., MacDonald, B., Fisher, M., Nater, U., . . Broadbent, E. (2017). A pilot randomized trial of a companion robot for people with dementia living in the community. Journal of the American Medical Directors Association, 18(10), 871-878. doi:10.1016/j.jamda.2017.05.019

Lindbergh, C., Dishman, R., \& Miller, L. (2016). Functional disability in mild cognitive impairment: A systematic review and meta-analysis. Neuropsychology Review, 26(2), 129-159. doi:10.1007/s11065-016-9321-5

Louie, W., \& Nejat, G. (2020). A social robot learning to facilitate an assistive group-based activity from non-expert caregivers INT J SOC ROBOT. doi:doi.org/10.1007/s12369-02000621-4

Matarić, M., \& Scassellati, B. (2016). Socially assistive robotics. Cham: Springer.

McGlynn, S., Geiskkovitch, D., Mitzner, T., \& Rogers, W. (2016). Paro's stress-reduction potential for older adults. Proceedings of the Human Factors and Ergonomics Society Annual Meeting, 60(1), 1799-1803. doi:10.1177/1541931213601411

Minichiello, V., Aroni, R., Timewell, E., \& Alexander, L. (1990). In-depth interviewing: Researching people. Hong Kong: Longman Cheshire.

Moyle, W., Jones, C., Murfield, J., Thalib, L., Beattie, E., Shum, D., \& Draper, B. (2017). Using a therapeutic companion robot for dementia symptoms in long-term care: Reflections from a cluster-rct. Aging \& Mental Health, 23(3), 329-336.

Orejana, J., MacDonald, B., Ahn, H., Peri, K., \& Broadbent, E. (2015). Healthcare robots in homes of rural older adults. Paper presented at the International Conference on Social Robotics, Cham.

Pearce, A. J., Adair, B., Miller, K., Ozanne, E., Said, C., Santamaria, N., \& Morris, M. E. (2012). Robotics to enable older adults to remain living at home. Journal of Aging Research, 538169. doi:10.1155/2012/538169

Pharmaceutical Group of the European Union. (2008). Targeting adherence. Improving patient outcomes in europe through community pharmacists' intervention. Retrieved from http://www.pgeu.eu/policy/5-adherence.html

Pino, M., Boulay, M., Jouen, F., \& Rigaud, A.-S. (2015). "Are we ready for robots that care for us?" attitudes and opinions of older adults toward socially assistive robots. Front Aging Neurosci., 7, 141. doi:10.3389/fnagi.2015.00141

Prensky, M. (2001). Digital natives, digital immigrants. On the Horizon, 9(5), 1-6.

Ritter, F., Baxter, G., \& Churchill, E. (2014). Foundations for designing user-centered systems: What system designers need to know about people. London: Springer.

Robinson, H., MacDonald, B., \& Broadbent, E. (2014). The role of healthcare robots for older people at home: A review. International Journal of Social Robotics, 6, 575-591. doi:10.1007/s12369-014-0242-2

Robinson, H., MacDonald, B., \& Broadbent, E. (2015). Physiological effects of a companion robot on blood pressure of older people in residential care facility: A pilot study. The Australasian Journal on Ageing, 34(1), 27-32. doi:10.1111/ajag.12099

Robinson, H., MacDonald, B., Kerse, N., \& Broadbent, E. (2013). Suitability of healthcare robots for a dementia unit and suggested improvements. Journal of the American Medical Directors Association, 14(1), 34-40. doi:10.1016/j.jamda.2012.09.006

Robocare. (2019). Retrieved from http://robocare.co.kr/

Ros, R., \& Espona, M. (2020). Exploration of a robot-based adaptive cognitive stimulation system for the elderly. Paper presented at the HRI '20: Companion of the 2020 ACM/IEEE International Conference on Human-Robot Interaction, Cambridge, United Kingdom.

Saunders, B., Sim, J., Kingstone, T., Baker, S., Waterfield, J., Bartlam, B., . . Jinks, C. (2018). Saturation in qualitative research: Exploring its conceptualization and operationalization. Quality \& Quantity, 52(4), 1893-1907. doi:10.1007/s11135-017-0574-8 
Scandurra, I., \& Sjölinder, M. (2013). Participatory design with seniors: Design of future services and iterative refinements of interactive ehealth services for old citizens. Med 2.0, 2, e12.

Schroeter, C., Mueller, S., Volkhardt, M., Einhorn, E., Huijnen, C., van den Heuvel, H., . . Gross, H. (2013). Realization and user evaluation of a companion robot for people with mild cognitive impairments. Paper presented at the IEEE International Conference on Robotics and Automation, Karlsruhe, Germany.

Sharkey, A., \& Sharkey, N. (2010). Granny and the robots: Ethical issues in robot care for the elderly. Ethics and Information Technology, 14(1), 27-40. doi:10.1007/s10676-010-92346

Shibata, T., \& Tanie, K. (2001). Physical and affective interaction between human and mental commit robot. Paper presented at the Proceedings of the IEEE International Conference on Robotics and Automation, Seoul, Korea.

Sokol, M., McGuigan, K., Verbrugge, R., \& Epstein, R. (2005). Impact of medication adherence on hospitalization risk and healthcare cost. Med Care, 43, 521-530.

Thomas, J., \& Harden, A. (2008). Methods for the thematic synthesis of qualitative research in systematic reviews. BMC Medical Research Methodology, 8(45). doi:10.1186/1471$2288-8-45$

Vandemeulebroucke, T., de Casterle, B., \& Gastmans, C. (2018). How do older adults experience and perceive socially assistive robots in aged care: A systematic review of qualitative evidence. Aging \& Mental Health, 22(2), 149-167.

Wang, S., Bolling, K., Mao, W., Reichstadt, J., Jeste, D., Kim, H., \& Nebeker, C. (2019). Technology to support aging in place: Older adults' perspectives. Healthcare, 7(60). doi:10.3390/healthcare7020060

Zsiga, K., Tóth, A., Pilissy, T., Péter, O., Dénes, Z., \& Fazekas, G. (2017). Evaluation of a companion robot based on field tests with single older adults in their homes. Assistive Technology, 30(5), 259-266. doi:10.1080/10400435.2017.1322158 


\section{List of Tables}

Table 1.

Types and descriptions of the daily reminders.

\begin{tabular}{ll}
\hline Reminder & Description \\
\hline Wake-up & $\begin{array}{l}\text { Reminds a person when to wake up. The robot tells the person the date } \\
\text { and time and reminds them all of their appointments for the day. }\end{array}$ \\
\hline Take medication & $\begin{array}{l}\text { Reminds a person to take their medications. Additional notes can be } \\
\text { added to provide detail on dosage or any other relevant information. }\end{array}$ \\
\hline Robot game & $\begin{array}{l}\text { This reminder refers to playing the three touch-screen games available } \\
\text { on the robot. }\end{array}$ \\
\hline Block game & \begin{tabular}{l} 
Reminder to play the three block games on the robot. \\
\hline Go out
\end{tabular} \\
\hline Visit & Reminds a person when to go out, such as for events or activities. \\
\hline Go to bed & Reminds the person when they are expecting a visitor. \\
\hline Recommend & $\begin{array}{l}\text { Provides recommendations to the user (i.e. to perform a task or } \\
\text { activity). }\end{array}$ \\
\hline Survey & Reminds the user to complete a survey (i.e. for monitoring purposes). \\
\hline
\end{tabular}


Table 2.

Summary of participants' demographics and time using the robot.

\begin{tabular}{llllll}
\hline Participant & Gender* & Ethnicity & $\begin{array}{l}\text { Age } \\
\text { (years) }\end{array}$ & $\begin{array}{l}\text { Time living in } \\
\text { village } \\
\text { (years) }\end{array}$ & $\begin{array}{l}\text { Time using } \\
\text { robot } \\
\text { (days) }\end{array}$ \\
\hline 1 & M & NZ European & 80 & 6.5 & 7 on/off \\
2 & F & NZ European & 74 & 6.5 & 7 on/off \\
3 & F & European & 79 & 2 & 6 on/off \\
4 & M & English & 81 & 2 & 7 \\
5 & F & Welsh & 83 & 2 & 7 \\
6 & F & NR. & 72 & 1 & 3.5 on/off \\
\hline
\end{tabular}

Notes:

$* M=$ male, $F=$ female

$N Z=$ New Zealand

$N R=$ not reported

On/off = the robot stayed in the house, but was turned off and on. 


\section{List of Figures}

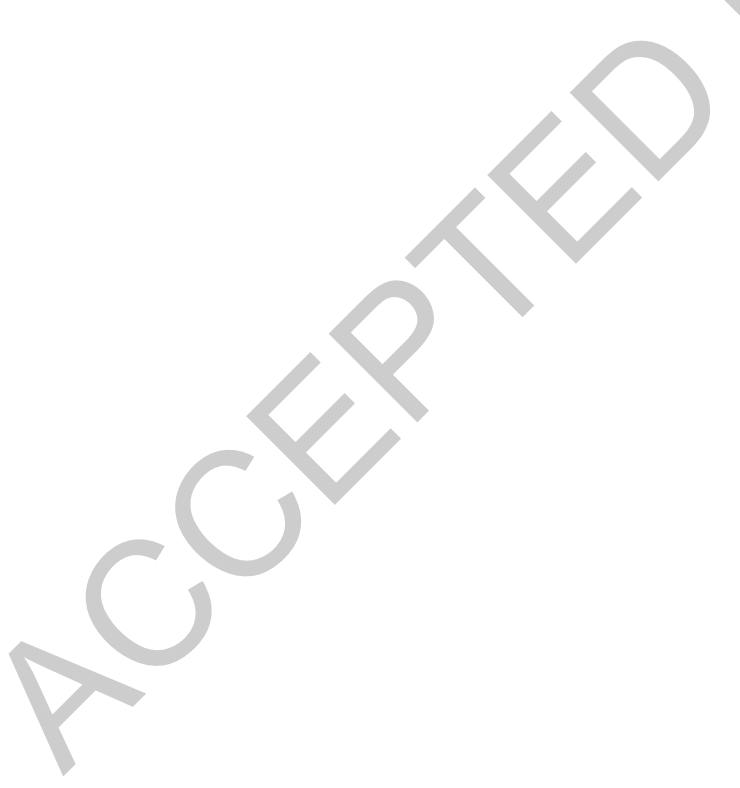



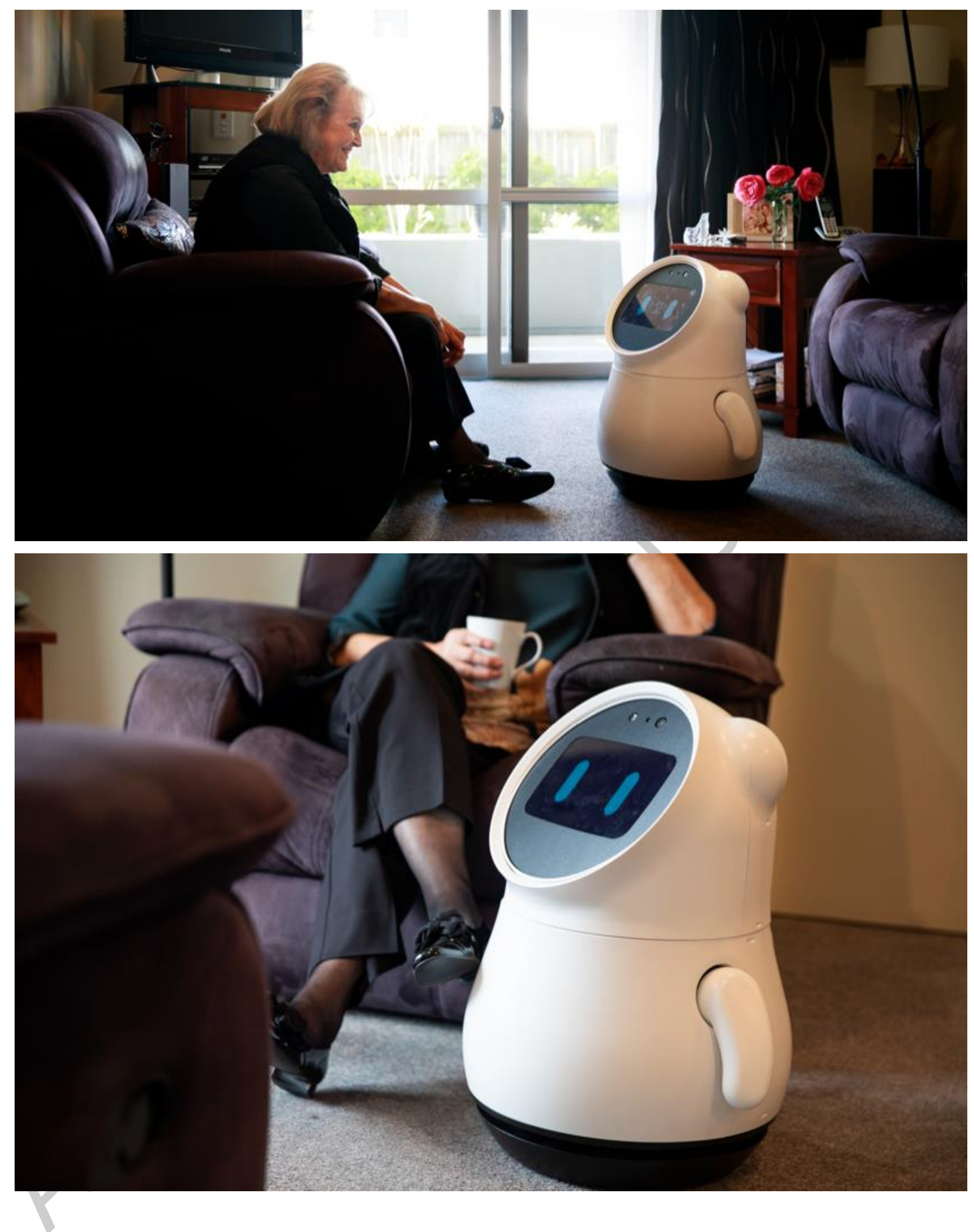

Figure 1. Photographs of Bomy, the dailycare robot used in the study, in a home environment. 

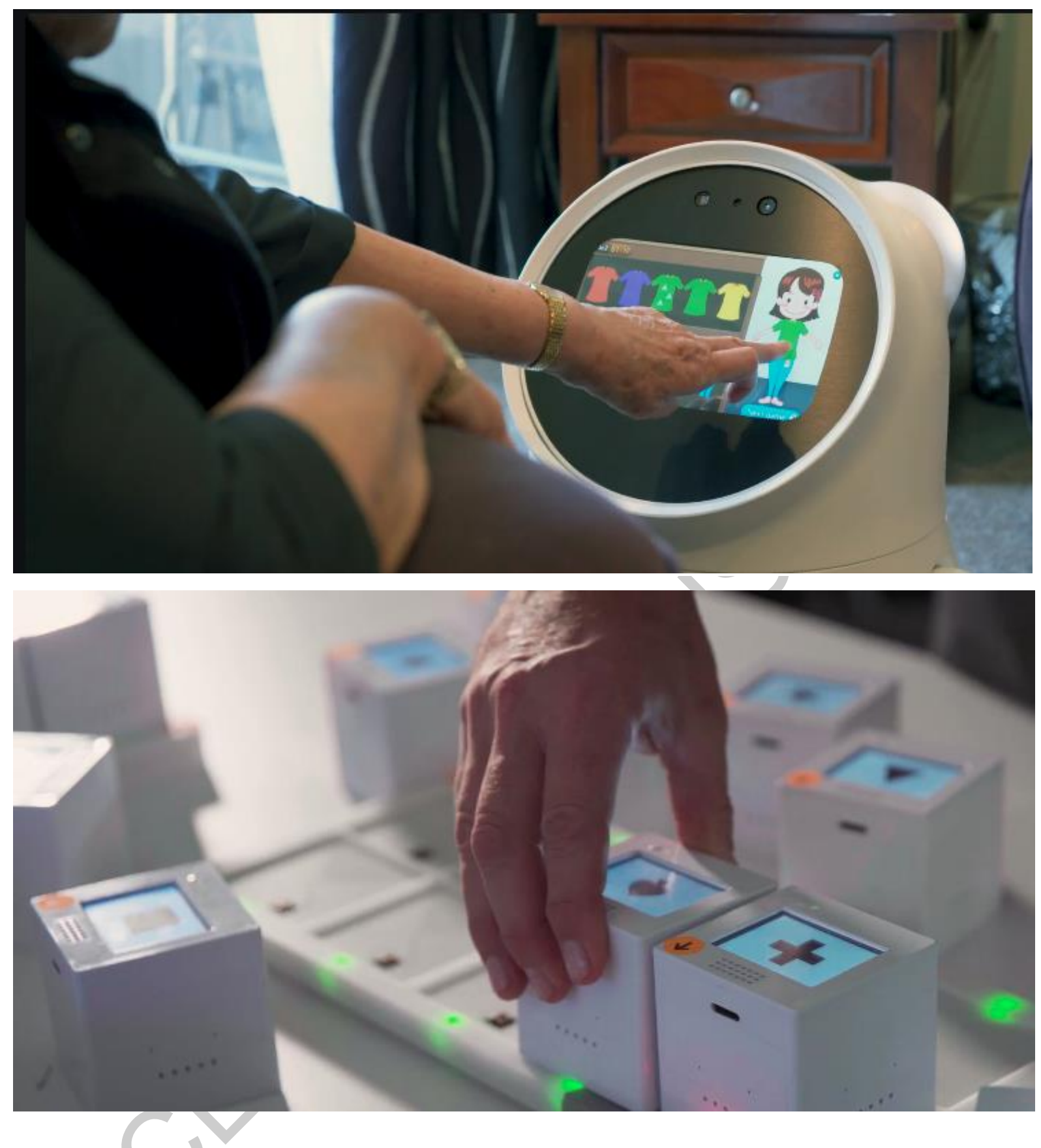

Figure 2. Photographs showing a screen game (above) and the interactive game blocks (below). 